\title{
Saberes docentes e 0 ensino da estatística: considerações sobre a ação pedagógica
}

\author{
Alessandra de Abreu Corrêa $a^{*}$
}

\section{Resumo}

O presente artigo apresenta um estudo acerca dos saberes docentes mobilizados pelos professores de matemática no ensino médio em suas práticas de ensino da estatística. O objetivo foi diagnosticar e compreender como os saberes docentes são construídos na prática pedagógica desses professores. Para fins deste estudo, foram examinados os saberes da ação pedagógica que emergiram das concepções docentes evidenciadas em um questionário, respondido por oito professores de matemática do ensino médio da cidade de Canela, estado do Rio Grande do Sul. A análise dos dados privilegiou o método conhecido como análise textual discursiva e caracterizou uma abordagem qualitativa, analítica e compreensiva. Segundo os docentes respondentes, o uso do livro didático e das tecnologias e informações que a mídia disponibiliza seriam algumas de suas principais ferramentas teóricas para ensinar estatística no ensino médio.

Palavras-chave: Educação. Saberes docentes. Saberes da ação pedagógica. Ensino de estatística. Ensino médio.

\section{Introdução}

O presente artigo derivou-se da análise dos saberes mobilizados pelos professores ao ensinarem estatística no ensino médio. Tal pesquisa justificou-se por duas questões, a saber: a prática profissional da pesquisadora e suas inquietações acadêmicas. No âmbito profissional, essa inquietação investigativa é decorrente da percepção de que o ensino da estatística tem ocupado lugar central junto aos currículos escolares, tanto na educação básica quanto no ensino superior, principalmente ganhando espaço significativo nas diversas modalidades de avaliação ex-

Recebido: 23/04/2013 - Aprovado: 30/06/2013

http://dx.doi.org/10.5335/rep.2013.3561

Mestra em Educação em Ciências e Matemática pela Pontifícia Universidade Católica do Rio Grande do Sul (PUCRS). E-mail: aleacorrea@yahoo.com.br. 
terna. Essa relevância dos conteúdos estatísticos na contemporaneidade justifica o empreendimento de uma investigação com professores do ensino médio, sobre suas práticas e concepções ligadas ao ensino desses saberes.

No âmbito acadêmico, a pesquisa buscou compreender as várias perspectivas que constituem a formação docente e ampliar o olhar sobre a questão, incluindo os saberes docentes como um campo significativo tanto para a constituição dos conhecimentos da área quanto para as possibilidades de estabelecimento de uma profissionalidade docente mais qualificada. Dessa forma, a pesquisa da qual este artigo deriva trata da docência no ensino médio e do ensino da estatística, tendo como questão norteadora: que saberes docentes estão presentes nas práticas pedagógicas dos professores de matemática do ensino médio ao ensinar estatística?

No movimento de constituição do campo metodológico dessa pesquisa, foram considerados úteis os conhecimentos, as concepções e as ideias sobre a formação docente, inspiradas, principalmente, no pesquisador canadense Maurice Tardif (2010). Tal perspectiva preocupa-se com a formação, com as práticas e com os saberes profissionais que os professores assumem em seu cotidiano de trabalho. $\mathrm{O}$ pesquisador compara os saberes docentes com "estoques de informações", pois acredita que estes necessitam estar em constantes mudanças, estas correlacionadas às perspectivas sociais, culturais e epistemológicas de tais saberes. Em sua avaliação, os saberes docentes encontram-se com movimentações individuais e sociais do professor e do sistema, ou seja, os elos construídos entre indivíduo (professor), sociedade e saberes docentes são denominados por Tardif (2010) de "fios condutores" para as pesquisas sobre a docência.

Dessa forma, esta pesquisa teve abordagem qualitativa, com uma dimensão analítica compreensiva. A estratégia desenvolvida foi a aplicação de questionários mistos, sendo sujeitos da investigação oito professores do ensino médio da cidade de Canela-RS. A escolha desses sujeitos deu-se com base nos seguintes critérios: a) ser professor da rede pública estadual ou da rede privada; b) ter formação em licenciatura em matemática (concluída ou em andamento); c) trabalhar com conteúdos estatísticos em suas práticas pedagógicas. Mediante a operacionalização desses critérios, foi possível traçar um perfil dos sujeitos da pesquisa. Dois eram do sexo masculino e seis do sexo feminino, $75 \%$ trabalham na rede pública estadual, tendo um tempo de docência entre dois e dez anos, e $75 \%$ têm graduação em licenciatura em matemática.

No que respeita às experiências profissionais, percepções e concepções dos respondentes em relação ao ensino da estatística, constatou-se que todos atribuem a esse conteúdo um lugar de relevância, justificando que conhecimentos estatísticos são importantes, pois estão presentes no cotidiano e nas avaliações de larga es- 
cala. Vale destacar, também, que, conforme os sujeitos desta pesquisa, os saberes estatísticos estão igualmente presentes em outras disciplinas, sendo expressos em gráficos e tabelas, cuja interpretação requer conceitos estatísticos. Quando questionados sobre o lugar que os conhecimentos estatísticos ocupam nos currículos de suas escolas, diversas respostas emergem. Quatro professores relatam que a estatística ocupa lugar apenas no terceiro ano do ensino médio. Um professor relata que, no plano de estudos de sua instituição, apresenta-se a partir da $5^{\text {a }}$ série ( $6^{\circ}$ ano) do ensino fundamental. Em outra escola, está presente no segundo ano do ensino médio. Dois professores, ainda, relatam que, em suas escolas, a estatística não está presente na grade curricular.

Do ponto de vista do tratamento das informações, foi implementada a análise textual discursiva (ATD) como estratégia analítica inspirada na contribuição metodológica de Moraes e Galiazzi (2007). Essa metodologia tem um amplo campo de abrangência, uma vez que toma como objetivos a compreensão e a (re)construção do conhecimento, assim como articula a subjetividade à fundamentação teórica. Sendo uma modalidade intermediária entre a análise de conteúdo desenvolvida por Bardin (1977) e a análise de discurso proposta por Orlandi (1999), a ATD apresenta como características as transformações auto-organizadas que buscam no objeto de pesquisa a emergência de novos sentidos, para os quais o pesquisador precisa estar receptivo, a fim de, por meio da escrita, expressar conhecimentos latentes ou que estavam por emergir.

Neste estudo, serão examinados, especificamente, os saberes derivados da ação pedagógica. Como hipótese a ser desenvolvida ao longo do texto, trabalha-se com a perspectiva de que os saberes que envolvem o livro didático e as mídias e suas tecnologias têm se apresentado como recursos fundamentais para a organização do trabalho docente no ensino de estatística nessa etapa da educação básica.

O artigo está organizado em duas seções. Na primeira, expõe-se a fundamentação teórica, onde são destacados os pesquisadores tanto na área da educação estatística como na área de estudos em docência, que são tomados como referências analíticas. Na segunda parte, que tem como subseções os resultados da pesquisa, são apresentadas diferentes teorizações quanto aos saberes da ação pedagógica mobilizados pelos docentes ao ensinar estatística.

\section{Educação estatística em perspectiva}

Nas pesquisas desenvolvidas no Brasil, consideram-se relevantes as produções de Fonseca (2004) e Lopes (2004, 2008, 2010), as quais têm procurado compreender a relevância de ensinar e aprender estatística e probabilidade na educação 
básica. Para esse momento, interessa pensar que o ensino médio está direcionado para a formação de um sujeito que seja capaz de questionar dados estatísticos que a mídia apresenta diariamente, que argumente por meio das definições abordadas no campo e que valide suas interpretações de forma coerente e crítica, utilizando informações e observações convincentes e embasadas teoricamente. Essa abordagem traz consigo marcas de diferentes grupos culturais de uma sociedade contemporânea em permanente mudança, na qual a inserção no mundo do trabalho e as relações interpessoais determinam os critérios e as estratégias de produção do conhecimento que devem ser adquiridos de forma diferenciada. Logo, entende-se que a educação estatística faz parte do contexto desses estudantes, e isso desafia a fazer um deslocamento para pensar a formação docente e suas práticas escolares.

Tomando como referência os estudos de Lopes (2008), considera-se importante pensar nos modos pelos quais o ensino de probabilidade e estatística podem se inscrever nas práticas pedagógicas contemporâneas, mobilizado pela perspectiva da resolução de problemas. Tal abordagem evidencia que os professores devem possuir o conhecimento daquilo que ensinam em profundidade, para, assim, organizá-lo de forma a estabelecer inter-relações entre conteúdo e aprendizado, levando em consideração o desenvolvimento cognitivo, o contexto e os sujeitos a serem ensinados.

Nessa perspectiva, existem relações a serem avaliadas. A primeira relação existente é entre as práticas de leitura e a atividade matemática, devendo a contextualização do ensino da matemática estar vinculada à realidade do aluno. Assim, evidencia-se o papel social da escola e do conhecimento matemático. Outra relação destacada pela autora é que o processo de construção do conhecimento desse público é marcado pelas suas vivências. Ou seja, no campo escolar, haverá espaços de confrontos onde serão expostas definições e argumentações de inúmeras práticas culturais e sociais.

Ainda, Lopes (2008) enfatiza que o ensino da estatística poderia estar voltado para a formação de conceitos e para a elaboração de procedimentos, métodos e modelos. Segundo a concepção da autora, seria significativo que o pensamento estatístico crítico estivesse presente para o ensino e a aprendizagem, isto é, que a educação estatística oportunizasse situações de aprendizagem nas quais o sujeito fosse o ator principal na construção de seus conhecimentos. Conforme Lopes, não se tem um único caminho possível, mas se pode produzir múltiplas possibilidades partindo das vivências individuais e coletivas, caminhando na construção de "cidadãos críticos, éticos e reflexivos" (2008, p. 75).

Sob um olhar de autores estrangeiros, Gal (2002) aponta os estudos estatísticos como ferramentas importantes para a formação de um cidadão capacitado a resolver situações-problema que estão presentes em seu cotidiano com melhor 
desempenho. Dessa forma, o autor enfatiza que a alfabetização estatística está diretamente vinculada a cinco elementos cognitivos, a saber, habilidades de alfabetização, estatístico, matemático, conhecimento do contexto e questão crítica e, ainda, componente de disposição formado por posição crítica, convicção e atitudes.

Seguindo na mesma linha de pensamento, a pesquisadora espanhola Carmen Batanero evidencia que:

En una sociedad cambiante e impredecible, como la que nos ha tocado vivir, nos sentimos inseguros sobre cuál es la mejor forma de preparar a los jóvenes y cuáles son las materias y contenidos que debemos enseñar. Lo que hoy nos puede parecer esencial y a lo que dedicamos una gran parte del tiempo de enseñanza, puede quedar obsoleto en un tiempo no muy lejano (2001, p. 4).

Desse modo, os saberes tanto do docente como do aluno são importantes à geração de novos caminhos na aprendizagem. Enfim, diante do que afirmam os autores, torna-se possível pensar a possibilidade de investigar a educação estatística no contexto da escola básica. Com base nessa composição teórica, nota-se a relevância e a potencialidade dessa temática para o desenvolvimento de uma educação crítica. $\mathrm{Na}$ seção a seguir, serão apresentadas as análises dos saberes da ação pedagógica.

\section{Saberes da ação pedagógica nas práticas docentes: uma análise}

Os saberes da ação pedagógica, segundo Pimenta (1999), provêm de diferentes áreas onde o conhecimento, as experiências, os conteúdos específicos pedagógicos e didáticos tornam-se importantes ferramentas presentes nas atividades cotidianas dos professores. A partir desse conjunto complexo de condições é que se constitui esse saber. A autora ressalta que as áreas precisam estar coesas e interligadas, uma vez que a principal função da utilização dos saberes é a constituição de uma aprendizagem baseada em práticas sociais - pressuposto importante para que os processos de aprendizagem consolidem-se.

Seguindo essa perspectiva, percebe-se que os saberes pedagógicos estão em constantes movimentos, em constantes mudanças e em constantes confrontações (PIMENTA, 1999). Isso desafia os docentes em seu ambiente de trabalho a pesquisar, a dialogar, a pensar em ações e atitudes que contribuam para o objetivo escolar. Dessa forma, apresentam-se como saberes que estão "na linha de frente", com os quais os docentes interagem constantemente e que são indissociáveis da sua formação e prática profissional (PIMENTA, 1999).

Pimenta, ainda, enfatiza que, com o contato entre os saberes educacionais e os vinculados à pedagogia, é possível que os docentes encontrem ferramentas e fomentem outras discussões para suas práticas. Vale ressaltar que ambas as áreas 
contribuem, com seus requisitos de experiência e conhecimento, para a construção de um profissional crítico-reflexivo.

Sobre o referido saber, Gauthier et al. apresentam outra concepção, enfatizando que "o saber da ação pedagógica é o saber experiencial dos professores a partir do momento em que se torna prático e que é testado através das pesquisas realizadas em sala de aula" (2006, p. 33). Dessa forma, o pesquisador coloca o saber da ação pedagógica como equivalente ao saber experiencial, porém, cabe ressaltar que entre ambos os saberes existem distinções (GAUTHIER et al., 2006). O saber experiencial, conforme Gauthier et al. (2006), leva o professor a acreditar e a elaborar quase um ritual de procedimentos para que a aprendizagem dos alunos seja efetiva. Porém, isso pode não ser a real explicação para aprendê-lo. Nesse sentido, "o que limita o saber experiencial é exatamente o fato de que é feito de pressupostos e de argumentos que não são verificados por meio de métodos científicos" (2006, p. 33).

Seguindo, os autores evidenciam que o professor produz saberes experienciais, utilizando-se de percepções, concepções, técnicas, bom senso e outras qualidades que o ofício, ao longo da carreira, vai lhe ensinando. A partir dessa concepção, o saber apresenta-se de modo individualista, não havendo a propagação desse conhecimento no conjunto dos profissionais. Por sua vez, também não há sistematização, o que poderia auxiliar outros docentes que buscam por orientações disciplinares, curriculares ou pedagógicas.

O fator que distingue esses saberes, segundo Gauthier et al. (2006), está relacionado à legitimação dessas experiências. Melhor explicando, enquanto os saberes docentes estiverem condicionados somente à sala de aula, não sendo pesquisados e validados pela comunidade científica, não poderão ser considerados como saberes da ação pedagógica, integrando-se à identidade profissional ${ }^{1}$ do professor. Os autores ressaltam, ainda, que "os saberes da ação pedagógica legitimados pelas pesquisas são atualmente o tipo de saber menos desenvolvido no reservatório de saberes do professor, e também, paradoxalmente, o mais necessário à profissionalização do ensino" (GAUTHIER et al., 2006, p. 34).

Esses saberes são os articuladores entre as práticas educativas e o papel que a instituição escolar possui. Dessa forma, o docente vale-se de um conjunto didático oferecido ou não pelas instituições de formação de professores, para atingir seus objetivos tanto pessoais como profissionais. Busca nos materiais - midiáticos e didáticos - informações que o auxiliem no processo de aprendizagem e que estejam condizentes ao contexto em que está inserido.

Quanto aos materiais midiáticos, o pesquisador Roger Silverstone (2002) evidencia que, independentemente de qualquer fator, a mídia está presente em nossas 
vidas, produzindo e convivendo com diferentes tipos de informação que, de alguma maneira, são absorvidas por todos os sujeitos de uma sociedade, tornando-os seres ativos em relação ao seu tempo histórico, participantes do contexto contemporâneo. A mídia torna-se uma ferramenta política, social, econômica e cultural que influencia vidas consideravelmente, por meio de informações escritas, eletrônicas ou visuais (SILVERSTONE, 2002). Dessa forma, o autor afirma que o meio midiático provoca ou deveria provocar discussões sobre

[...] questões que emergem do simples reconhecimento de que nossa mídia é onipresente, diária, uma dimensão essencial de nossa experiência contemporânea. É impossível escapar à presença, à representação da mídia. Passamos a depender da mídia, tanto impressa como eletrônica, para fins de entretenimento e informação, de conforto e segurança, para ver algum sentido nas continuidades de experiência e também, de quando em quando, para as intensidades da experiência (SILVERSTONE, 2002, p. 12).

Analisando os modos pelos quais as mídias inserem-se nas práticas educacionais, em geral, e no ensino de estatística, em particular, é possível perceber que conceitos e gráficos estatísticos estão presentes nos mais variados assuntos e notícias apresentados em jornais, revistas, meios digitais e televisivos. Talvez isso demonstre que a mídia pode constituir-se como mais uma ferramenta para os docentes fazerem uso nos processos de ensino e de aprendizagem da estatística.

Após uma breve incursão sobre o assunto, toma-se como definição, para esse momento, que saberes da ação pedagógica são os recursos produzidos e utilizados pelos docentes, com base em suas experiências profissionais, para efetivar sua prática profissional. No que tange ao ensino de estatística, conforme será evidenciado posteriormente, observou-se que os docentes do ensino médio, ao ensinarem tais conteúdos, fazem uso de recursos midiáticos e didáticos para contextualizar e ensinar a estatística, sendo tais recursos adquiridos por meio do exercício da docência ou na sua formação acadêmica. Desse modo, os saberes mobilizados nesse campo estão dispostos em dois eixos: o uso dos livros didáticos e das tecnologias e as informações que as mídias disponibilizam.

\section{Livros didáticos: interlocutores no ensino da estatística}

O livro didático talvez seja um dos mais antigos instrumentos de propagação do conhecimento escolar, pois, independentemente da época ou da cultura, em suas páginas ficavam registradas "as verdades, anseios e descobertas" de um determinado tempo e geração (BITTENCOURT, 2008, p. 13). A primeira formulação indicativa desse material foi produzida por Comenius, no século XVI. O livro panmetódico, proposto pelo pensador clássico, apresentava-se como uma estratégia para 
que todos aprendessem os conteúdos desde uma mesma sequência, do mais simples ao mais complexo (NARODOWSKI, 2006). Assim, tal produto apresentava-se como um meio de registro para as produções culturais já consolidadas, convertendo-as em conhecimentos escolares. Por meio desses registros, a humanidade apropriou-se dos diferentes fatos e saberes, conhecimentos científicos que, impressos, ganharam significados e representações diferentes.

Bittencourt (2008) apresenta o livro didático por meio de quatro perspectivas. A primeira, como mercadoria, na qual o mercado incentiva a fabricação e comercialização, atendendo as suas demandas com base em técnicas cada vez mais elaboradas, ou seja, torna-se um produto destinado ao mundo dos negócios. A segunda perspectiva elucida que o livro didático pode ser "um depositário dos diversos conteúdos educacionais, suporte privilegiado para recuperar os conhecimentos e técnicas consideradas fundamentais por uma sociedade em determinada época" (BITTENCOURT, 2008, p. 14). Na terceira perspectiva, a autora refere-se ao livro didático como uma ferramenta pedagógica e, para aprofundá-la, faz uso das palavras de Choppin (1980). Segundo esse autor, o livro didático está "inscrito em uma longa tradição, inseparável tanto na sua elaboração como na sua utilização das estruturas, dos métodos e das condições do ensino de seu tempo" (CHOPPIN, 1980 apud BITTENCOURT, 2008, p. 14). E, por último, Bittencourt (2008) destaca que o livro é uma fonte condutora de valores e de ideias de uma cultura.

Dessa forma, o livro didático pode ser visto como um interlocutor entre docente, aluno e conhecimento. Entretanto, entende-se que não deva ser considerado como a única ferramenta para esse diálogo, devendo o professor ter e estabelecer limites entre a sua autonomia pedagógica e o livro didático. Pode, dentro do possível, adaptar e complementar informações que acredita ser relevantes para seus alunos, ou, ainda, eliminar as irrelevantes e, assim, tornar os conteúdos didáticos compreensíveis e partes integrantes do contexto escolar. Ou seja, o papel do docente diante do livro didático pode ser o de mediador dos conteúdos e o do aluno, o de receptor que assimila, transforma e ressignifica as informações, de acordo com suas percepções e seus conhecimentos prévios (BITTENCOURT, 2008).

Sobre o livro didático de matemática, especificando essa argumentação, Dante (1996) aponta pontos positivos para a sua utilização e para a obtenção de resultados efetivos no ensino e na aprendizagem. Para o aluno, o livro didático apresenta definições, propriedades, tabelas, problemas, atividades e exercícios que podem lhe auxiliar na aprendizagem, sendo os conteúdos sempre sequenciados e dependentes entre si. Em geral, o livro didático apresenta os conteúdos nessa ordem, e, por meio da resolução de problemas e atividades, o aluno poderá desenvolver conceitos e habilidades essenciais para a aprendizagem (DANTE, 1996). Percebe-se que, para 
o autor, o aluno é capaz de aprender utilizando os livros didáticos que apresentam sequencialmente os conteúdos de forma completa (definições, propriedades, entre outras), desenvolvendo, assim, as habilidades e competências necessárias para sua aprendizagem em matemática.

Outra função do livro seria auxiliar o professor com atividades desafiadoras, textos explicativos e históricos, ou seja, o livro didático - que em muitos casos é o único recurso que a escola tem a oferecer ao professor e aluno - se torna uma ferramenta (DANTE, 1996). Nesse ponto, faz-se possível relacionar professor e livro didático, notando-se que este é sugerido como um instrumento indispensável àquele, nem sempre, contudo, privilegiando as potencialidades e o conhecimento desse profissional.

Porém, o autor também afirma, em seu texto intitulado Livro didático de matemática: uso e abuso?, que "o livro didático, embora não deva ser o único, é um dos instrumentos essenciais na aprendizagem em sala de aula” (DANTE, 1996, p. 88). Assim, é necessário que o docente faça uso do livro de maneira equilibrada e racional, que pode ser iniciada com a escolha das obras oferecidas pelo Programa Nacional do Livro Didático (PNLD), criado em 1929 com outra denominação. Esse programa, em primeiro lugar, está voltado para a distribuição de livros didáticos para estudantes da rede pública das diferentes etapas da educação básica (sobretudo ensinos fundamental e médio). Conjuntamente ao PNLD, desde 2007, com a criação do Fundo de Manutenção e Desenvolvimento da Educação Básica e de Valorização dos Profissionais da Educação (Fundeb), a educação infantil e o ensino médio também passaram a receber tais materiais didáticos, gradativamente, em todas as áreas do conhecimento.

No Guia de livros didáticos: PNLD 2008 - matemática, nota-se outra visão sobre o assunto, enfatizando que o livro didático tem como funções

oferecer informações e explicações sobre o conhecimento matemático que interfere e sofre interferências das práticas sociais do mundo contemporâneo e do passado. Também deve conter uma proposta pedagógica que leve em conta o conhecimento prévio e o nível de escolaridade do aluno e que ofereça atividades que o incentivem a participar ativamente de sua aprendizagem e a interagir com seus colegas. Além disso, o livro precisa assumir a função de texto de referência tanto para o aluno, quanto para o docente (BRASIL, 2007, p. 9).

Esse mesmo guia (BRASIL, 2007), ao citar os pesquisadores Gérard e Roegiers, enuncia outras funções específicas do livro didático para o aluno e para 0 docente. Para o aluno, as principais funções são: 
favorecer a aquisição de conhecimentos socialmente relevantes; propiciar o desenvolvimento de competências cognitivas, que contribuam para aumentar a autonomia; consolidar, ampliar, aprofundar e integrar os conhecimentos adquiridos; auxiliar na autoavaliação da aprendizagem; contribuir para a formação social e cultural e desenvolver a capacidade de convivência e de exercício da cidadania (GÉRARD; ROEGIERS, 1998 apud BRASIL, 2007, p. 11-12).

Para os docentes, as funções seriam de outro nível:

auxiliar no planejamento e na gestão das aulas, seja pela explanação de conteúdos curriculares, seja pelas atividades, exercícios e trabalhos propostos; favorecer a aquisição dos conhecimentos, assumindo o papel de texto de referência; favorecer a formação didático-pedagógica; auxiliar na avaliação da aprendizagem do aluno (GÉRARD; ROEGIERS, 1998 apud BRASIL, 2007, p. 12).

Por meio desses apontamentos, percebe-se o porquê das discussões que cercam o assunto, as divergências e as convergências na escolha e utilização desse objeto. O fato é que, antes mesmo da invenção da imprensa, constata-se que o livro didático integra a cultura e as transformações que nela imperam. Por meio de suas imagens, seus escritos, textos e contextos, o conhecimento é disseminado, constituindo-se como um mediador entre os sujeitos aprendentes e a sociedade do seu tempo. O seu design e sua função de aprendizagem levam a que o sujeito volte suas atenções, habilidades e competências diretamente a ele, o que propicia o ensino de qualquer assunto em qualquer sociedade.

Cabe reiterar que, em muitos casos, os livros didáticos são considerados "bíblias" do currículo, não somente pelos professores, mas também pelas instituições escolares que fazem dele seu principal orientador para a elaboração da grade curricular, quando objetivos, ordem de conteúdos e avaliações, dentre outros requisitos, são retirados das páginas desses materiais (BITTENCOURT, 2008). Diante desse suposto exagero, o livro talvez deixe de cumprir o seu papel que, segundo Choppin (2004), consistiria em sistematizar os referenciais - ideológicos e culturais -, instrumentalizar e documentar os conteúdos escolares.

Choppin (2004) destaca que, historicamente, o livro didático tem funções que se associam a fatores de ordem social, econômica, cultural, temporal, política, entre outras. A primeira função, denominada pelo autor de função referencial, trata 0 livro didático como uma cópia do programa curricular a ser seguido e argumenta que, "em todo o caso, ele constitui o suporte privilegiado dos conteúdos educativos, o depositário dos conhecimentos, técnicas ou habilidades que um grupo social acredita que seja necessário transmitir às novas gerações" (CHOPPIN, 2004, p. 553).

A segunda função do livro tem como objetivo auxiliar, facilitar, favorecer a implantação de métodos de aprendizagem por meio de exercícios ou atividades que visam à apropriação de competências e habilidades, para posteriormente serem 
ferramentas para as metodologias escolares, recebendo o nome de função instrumental (CHOPPIN, 2004, p. 553).

Como próxima função, Choppin (2004) enaltece a influência cultural e a ideologia que os livros apresentam de uma determinada sociedade, sendo possível, segundo a visão do autor, afirmar que o livro didático é:

Instrumento privilegiado de construção de identidade, geralmente [...] reconhecido, assim como a moeda e a bandeira, como um símbolo da soberania nacional e, nesse sentido, assume um importante papel político. Essa função, que tende a aculturar - e, em certos casos, a doutrinar - as jovens gerações, pode se exercer de maneira explícita, até mesmo sistemática e ostensiva, ou, ainda, de maneira dissimulada, sub-reptícia, implícita, mas não menos eficaz (CHOPPIN, 2004, p. 553).

Como quarta e última função, o mesmo autor aponta que o livro, nos contextos escolares, geralmente é visto como um formador de opinião, sendo possível que o aluno desenvolva a autonomia e a criticidade por meio da leitura livre. Assim, o livro assume uma função documental no processo de aprendizagem. Essa posição que lhe é atribuída mostrou-se bastante recorrente nos materiais empíricos e pode ser lida nos excertos a seguir.

Sujeito 4 - Com as situações-problema que a maioria dos livros traz é possível relacionar o conteúdo com outras disciplinas, principalmente com geografia e biologia. O livro com seus gráficos e exemplos ajudam a fazer isso. Para os conteúdos da estatística também é bom, porque os livros sempre trazem as questões de vestibular e agora do Enem.

Sujeito 3 - Os alunos da $3^{\mathrm{a}}$ série, depois de estudarem no livro um determinado assunto, pediram se podiam fazer um trabalho para ver a situação do seu bairro e depois analisar os dados, conforme o livro. As atividades do livro ajudaram para ligar a escola com a vida dos alunos, isso não é bom?

Sujeito 7 - Procuro atividades em mais de um livro didático para os meus alunos realizarem e também uso textos de jornais e revistas para lermos e analisarmos se o que está ali impresso pode ser validado ou se somente é um gráfico bonitinho que não serve para nada.

Nota-se que o livro didático ainda se apresenta como um recurso (indispensável), difundido nas aulas de estatística do ensino médio. Uma das razões para isso talvez resida no fato de ser acessível a praticamente todos os alunos das escolas brasileiras, distribuído ora em larga escala pelas políticas de estado para as escolas públicas, ora nos pacotes de apostilamento do ensino produzidos por grandes grupos empresariais que atuam na educação - movimento típico das escolas particulares do país. Porém, Dante afirma que o livro didático deve ser considerado pelo professor como "um meio, e não o fim em si mesmo" (1996, p. 89), é preciso que o docente realize uma releitura do conhecimento matemático presente no livro. Sendo uma ferramenta de fácil manuseio, seus conteúdos, em geral, 
e, especificamente, os de estatística são atualizados e trazem situações-problema que se aproximam do cotidiano dos estudantes. Enfim, a partir de uma tradição pedagógica já consolidada no Brasil, os professores do ensino médio, ao ensinarem estatística, seguem atribuindo centralidade ao uso dos livros didáticos na composição pedagógica de suas aulas.

Observa-se que, independentemente da função que exerça, ou que possa a vir a ter, o livro didático garante espaço para as ciências dialogarem entre si, permitindo que diferentes saberes sejam mobilizados (CHOPPIN, 2004). Inicialmente, dentro do esperado, o professor é quem mobiliza esses saberes, pois necessita perceber as limitações que o instrumento apresenta diante do contexto escolar adequando ênfases e atividades à realidade escolar. Em outras palavras, tais saberes necessitam estar presentes para fazer do livro didático um representante do conhecimento científico no meio escolar. A seguir será apresentado outro saber da ação pedagógica: o uso das tecnologias e informações que as mídias disponibilizam.

\section{Tecnologias e informações midiáticas: fontes de informações no ensino da estatística}

Para iniciar esta seção, recorre-se a Silverstone (2002), a fim de dialogar acerca da importância e da influência que a mídia exerce sobre as pessoas na contemporaneidade. Segundo o autor, a importância da mídia está no fato de que, por meio dela, torna-se possível a compreensão, não só na "dimensão social e cultural, mas também política e econômica, do mundo moderno" (2002, p. 13), assim como a produção e o compartilhamento de significados, em que todos têm acesso à expressão de seus argumentos, sendo estes aceitos ou não. Em outras palavras, a mídia exige de nós o desenvolvimento da capacidade crítica e reflexiva, sendo as variáveis envolvidas no meio midiático bastante complexas. Quanto à influência da mídia, Silverstone afirma:

É no mundo mundano que a mídia opera de maneira mais significativa. Ela filtra e molda realidades cotidianas, por meio de suas representações singulares e múltiplas, fornecendo critérios, referências para a condução da vida diária, para a produção e a manutenção do senso comum (2002, p. 20).

Percebe-se com essas palavras que a mídia, independentemente do cotidiano que experienciamos, integra-se à "realidade em que participamos" (SILVERSTONE, 2002, p. 21). Consequentemente, por meio dos intercâmbios cotidianos com outros sujeitos, passa-se a interpretar os fatos com base no senso comum. Deslocando-se ao encontro das questões escolares sobre a mídia, mais precisamente 
sobre os saberes estatísticos que esta explicita, pode-se observar a publicização de um conjunto de gráficos e conceitos estatísticos, preponderando média, mediana, desvio padrão, nível de confiabilidade, entre outros.

Observa-se que os meios de comunicação divulgam, em uma proporção considerável, suas informações remetendo-se a pesquisas estatísticas, tais como índices de crescimento econômico, demográfico, de mortalidade infantil, aumento de preço dos combustíveis, enfim, questões populacionais e econômicas em geral. Importa destacar que, no Brasil, o Instituto Brasileiro de Geografia e Estatística (IBGE) é o órgão oficial responsável pelas informações estatísticas que norteiam os estudos e planejamentos nacionais. Decisões baseadas nesses dados, tabulados e representados graficamente, são importantes para as políticas públicas governamentais, que constroem e traçam suas metas podendo vislumbrar consequências posteriores à aplicação de suas ações.

Um fator que leva a mídia a utilizar a estatística, segundo Cazorla (2004), é que os dados expressos numericamente têm a capacidade de concentrar e transformar muitos elementos em uma única informação, sendo de fácil interpretação e representação. Porém, sabe-se que a estatística baseia-se em amostras e estimativas, ou seja, as conclusões realizadas podem não apresentar resultados precisos, uma vez que as variáveis que fundamentam os resultados são modificáveis, dependendo do objetivo que se quer atingir.

A partir desses apontamentos, percebeu-se que o papel do docente no processo de aprendizagem da estatística vai além do ensino da teoria e da prática. Faz-se necessário que o professor a referencie como uma das muitas ferramentas de tomadas de decisões, pondo sobre as informações um olhar crítico e reflexivo. Com efeito, segundo Lopes, “[...] a estatística, com seus conceitos e métodos, configura-se com um duplo papel: permite compreender muitas das características da complexa sociedade atual, ao mesmo tempo que facilita a tomada de decisões em um cotidiano onde a variabilidade e a incerteza estão sempre presentes" (2010, p. 51).

Uma das formas estatísticas que os meios midiáticos exploram é o gráfico. Conforme Cazorla, os gráficos contribuem para "descrever, explorar e resumir um conjunto de dados, mesmo quando estes representam grande conjunto de dados" $(2004$, p. 5). De forma clara e sistemática, as informações quantitativas são consideradas pelo autor como uma das maneiras mais eficazes para comunicar informações. Com isso, o processo de aprendizagem sobre gráficos não deve se resumir somente na construção desses recursos, mas também na interpretação dos dados que o geraram e do seu entorno. O autor evidencia que isso é possível se o professor relaciona suas competências pedagógicas, seus saberes estatísticos e o contexto da situação; caso contrário, o processo de ensino-aprendizagem vai apresentar fragilidades (CAZORLA, 2004). 
Para auxiliar o docente no ensino da estatística, uma ferramenta a que se recorre são os recursos da multimídia, múltiplos recursos técnicos disponibilizados a partir das novas tecnologias da informação e da comunicação (TICs). Conforme Alves e Cunha (2007), o computador é um desses agentes mais significativos, na medida em que se apresenta de forma multissensorial, integrada, intuitiva e interativa. Tal tecnologia apresenta informações que atendem, de forma direta ou indireta, aos diversos enfoques do processo de ensino-aprendizagem. Porém, cabe a ressalva de que esse fato ocorrerá se o programa de multimídia estiver em consonância com os objetivos pedagógicos (ALVES; CUNHA, 2007).

O computador também é visto, no sistema educacional, como um instrumento que complementa, aperfeiçoa e qualifica a aprendizagem, pois, em nossa sociedade, as informações e os conhecimentos estão em constante mutação e o computador acompanha com seus recursos multimidiáticos esse processo. Frente a isso, Charlot argumenta que a tecnologia tem como função a organização das informações.

A informação é um dado exterior ao sujeito que pode ser armazenada, estocada, inclusive em um banco de dados. O conhecimento é o resultado de uma experiência pessoal ligada à atividade de um sujeito provido de qualidades afetivo-cognitivas, e intransmissível, e uma informação de que o sujeito se apropria (CHARLOT, 2000, p. 61).

Segundo Charlot (2000), a máquina, por si só, no campo educacional, não ensina ninguém; o aluno deve buscar e empregar as informações disponíveis. Nessa perspectiva, o professor é entendido como o responsável pela produção de condições adequadas de aprendizagem, ou seja, ele se torna o construtor dos ambientes de aprendizagem, tendo em vista a criação de situações desafiadoras, e o mediador entre a aprendizagem e a ampliação do intelecto do aluno.

Além disso, se possível, o professor deve utilizar os ambientes computacionais visando a alcançar seus objetivos, pois estes são amplos e repletos de informações que, muitas vezes, não vão ao encontro das finalidades pretendidas. Assim, aspectos teóricos e práticos devem ser levados em consideração no momento de fazer uso de um software educacional ou dos recursos por eles disponibilizados (CHARLOT, 2000). Com o uso de planilha eletrônica nas aulas de estatística, por exemplo, os alunos podem obter outras perspectivas sobre uma mesma situação-problema, podem avaliar e reavaliar, caso seja necessário, os dados e as informações geradas, ocorrendo um deslocamento do conhecimento que poderá ser estendido para outras áreas do campo educacional.

Em suas respostas aos questionários, os professores evidenciam, de modo geral, a opção pelo uso de meios tecnológicos para o ensino e a aprendizagem da estatística. Os fragmentos a seguir elucidam essa perspectiva. 
Sujeito 5 - Utilizo o Excel por apresentar ferramentas, tabelas e também de gráficos, o que ajuda na visualização dos alunos.

Sujeito 2 - O jornal apresentou uma tabela com a quantidade de delitos por cidade da região. Os alunos da $3^{\mathrm{a}}$ série do ensino médio criaram vários gráficos demonstrativos gerais dos municípios onde apresentavam o maior número de delitos e quais os delitos que ocorreram com maior frequência.

Sujeito 3 - Inicialmente o aluno retira um gráfico ou uma tabela de revistas ou jornais, a partir disso ele é conduzido a fazer leitura através de comparações e análise do mesmo, para depois ter uma visão crítica das situações apresentadas.

Percebeu-se que a mídia e os meios tecnológicos são fontes consultadas e utilizadas pelos docentes no ensino e na aprendizagem da estatística no ensino médio. Por serem produtos contemporâneos de fácil acesso, manipulação e/ou aquisição, as revistas e os jornais impressos ou televisivos detêm a função de informar. Assim, uma grande parcela dessas informações são notícias impregnadas de conceitos e representações estatísticas que fazem parte do cotidiano, influenciando-o e tornando o conhecimento estatístico quase indispensável.

Uma possível justificativa para esse fato, conforme Cazorla (2004), é que os números expressam confiabilidade e racionalidade, e a estatística, entre muitos, é vista dessa maneira. Partindo disso, os professores vislumbram nos programas computacionais um recurso que, por meio das funções que contemplam (incluindo os gráficos), auxilia no ensino e na aprendizagem dos conceitos estatísticos.

No ensino da estatística, segundo Tajra (2001), um dos programas utilizados é a planilha eletrônica Excel ${ }^{\circledR 4}$, na qual os alunos, para obterem resultados, devem definir que funções empregar. Além disso, o programa elabora gráficos que auxiliam na compreensão das informações. Porém, a autora ressalta que o Excel $^{\circledR}$ deve ser utilizado após a compreensão dos conceitos estatísticos, pois as funções que oferece são simplificadas e, sem conhecimento anterior, os conceitos não serão entendidos adequadamente.

Cabe destacar, conforme os docentes participantes da pesquisa, que esse processo é concomitante à utilização dos materiais que a mídia e os meios tecnológicos disponibilizam. Em outras palavras, o ensino da estatística no ensino médio está vinculado a contextos atuais nos quais a análise e a compreensão dos dados e gráficos partem das informações que são publicadas nas diferentes mídias.

\section{Considerações finais}

Ao finalizar este texto sobre os saberes mobilizados pelos docentes ao ensinarem estatística no ensino médio, algumas considerações emergem. Inicialmente, ressalta-se a importância que a estatística possui nos currículos nacionais desse segmento de escolarização e nas situações do cotidiano, as quais ocupam e estão 
inseridas em largo espaço praticamente em todas as ciências. Em segundo lugar, enaltece-se que os saberes docentes são constituídos por múltiplas dimensões, sendo cada uma delas fundamental nas práticas profissionais dos professores. Observando o contexto da pesquisa, nesse momento, é possível afirmar que são os saberes da ação pedagógica que estão presentes nos depoimentos dos docentes e fazem parte de suas práticas, as quais apresentam como pano de fundo pressupostos teóricos que orientam esses saberes, dentre os quais predominam aqueles voltados ao uso do livro didático e das tecnologias e informações disponibilizadas na mídia. Cada um desses instrumentos apresenta especificidades, entretanto, importa destacar que seu foco deverá estar nas relações de ensino e de aprendizagem que buscam vincular conhecimentos estatísticos com os cotidianos dos estudantes. Nessa direção, será possível que os alunos compreendam a importância da estatística no currículo escolar e, consequentemente, em sua formação como cidadãos.

\section{Teaching knowledge and teaching of statistics: considerations on the pedagogical action}

\section{Abstract}

This article presents a study about teaching knowledge mobilized by mathematics teachers in high school in their teaching practices of statistics. The objective was to diagnose and understand how teacher knowledge is constructed in the pedagogic practice of these teachers. For this study, were examined knowledges of the pedagogical action that emerged from teachers' conceptions evidenced in a questionnaire, which was answered by eight High School Mathematics teachers from the city of Canela, Rio Grande do Sul. The data analysis has privileged the method known as discursive textual analysis and is characterized as a qualitative, analytical and comprehensive approach. According to teachers, the use of textbooks and the use of technology and information that the media provides would be some of their main theoretical tools to teach statistics in high school.

Keywords: Education. Teaching knowledges. Knowledge of pedagogical action. Teaching of statistics. High school.

\section{Notas}

1 Para o presente momento, não serão mencionados conceitos sobre identidade profissional, pois se trata dos saberes docentes o tema em evidência. Porém, indicou-se o assunto pelo fato de os autores acreditarem que a identidade profissional tem relação com os saberes da ação pedagógica (GAUTHIER et al., 2006).

2 Microsoft Office Excel (patenteado pela Microsoft Corporation) é um programa de planilha eletrônica de cálculo que tem recursos de cálculos estatísticos, assim como ferramentas para a construção de tabelas e gráficos. 


\section{Referências}

ALVES, Hélder; CUNHA, Luís Miguel. Uma introdução a alguns aplicativos, numa abordagem inicial dos dados. Porto: Alea, 2007.

BARDIN, Laurence. Análise de conteúdo. Lisboa: Edições 70, 1977.

BATANERO, Carmen. Didática de la estadística. Granada: Grupo de Investigação em Educación Estadística do Departamento de Didática de la Matemática da Universidad de Granada, 2001. BITTENCOURT, Circe. Livro didático e saber escolar (1810-1910). Belo Horizonte: Autêntica, 2008 .

BRASIL. Ministério da Educação e Cultura. Guia de livros didáticos: PNLD 2008 - matemática. Brasília: MEC, 2007.

CAZORLA, Irene Maurício. Educação estatística aplicada à educação. Módulo de Estatística Aplicada à Educação. Salvador: Faculdade Jorge Amado, 2004.

CHARLOT, Bernard. Da relação com o saber: elementos para uma teoria. Porto Alegre: Artmed, 2000.

CHOPPIN, Allain. História dos livros e das edições didáticas: sobre o estado da arte. Revista Brasileira de Educação, São Paulo, v. 30, n. 3, p. 549-566, set./dez. 2004.

DANTE, Luiz Roberto. Livro didático de matemática: uso e abuso? Em Aberto, Brasília, v. 16, n. 16, p. 83-90, jan./mar. 1996.

FONSECA, Maria Conceição Ferreira Reis. A educação matemática e a ampliação das demandas de leitura e escrita da população brasileira. In: (Org.). Letramento no Brasil: habilidades matemáticas. São Paulo: Global, 2004. p. 11-30.

GAL, Iddo. Adult's statistical literacy: meanings, components, responsibilities - appeares. Internacional Statistical Review, Espanha, v. 70, n. 1, p. 1-33, 2002.

GAUTHIER, Clermont et al. Por uma teoria da pedagogia: pesquisas contemporâneas sobre os saberes docentes. Ijuí, RS: Ed. Unijuí, 2006.

LOPES, Celi Espandin. Literacia estatística e INAF 2002. In: FONSECA, Maria Conceição Ferreira Reis (Org.). Letramento no Brasil: habilidades matemáticas. São Paulo: Global, 2004. p. 187-200.

. O ensino da estatística e da probabilidade na educação básica e a formação dos professores. Cadernos Cedes, Campinas, v. 28, n. 74, p. 57-73, abr. 2008.

Os desafios para educação estatística no currículo de matemática. In: LOPES, Celi Espasadin et al. Estudo e reflexões em educação estatística. Campinas: Mercado das Letras, 2010. p. 47-64.

MORAES, Roque; GALIAZZI, Maria do Carmo. Análise textual discursiva. Ijuí, RS: Unijuí, 2007. NARODOWSKI, Mariano. Comenius \& a educação. Belo Horizonte: Autêntica, 2006.

ORLANDI, Eni Puccinelli. Análise de discurso: princípios e procedimentos. São Paulo: Pontes, 1999.

PIMENTA, Selma Garrido. Formação de professores: identidade e saberes da docência. In: . (Org.). Saberes pedagógicos e atividade docente. São Paulo: Cortez, 1999. p. 15-34.

SILVERSTONE, Roger. Por que estudar a mídia? São Paulo: Loyola, 2002.

TAJRA, Sanmya Feitosa. Informática na educação. São Paulo: Érica, 2001.

TARDIF, Maurice. Saberes docentes e formação profissional. Rio de Janeiro: Vozes, 2010. 